\title{
Exploring the Technological Readiness of Bulgarian Entrepreneurs to Create New Generation of Value-Added Chains ${ }^{1}$
}

Bozhidar I. Hadzhiev*

Valentina Nikolova-Alexieva $^{* *}$

\section{Abstract}

The theory and practice of broadband entrepreneurship has already become a fact. As stated in some pieces of research, ,.... In the modern world of business, entrepreneurship is becoming increasingly broadband and affects the creation of changes in every business space, at every level in every industrial and territorial dimension". This is entrepreneurship driven by broadband shopping of goods and services, instant communications, negotiations and orders. It is based on the ideas of Complex Reengineering theory, the three-star model and the seven concepts of this theory.

This study examined the technological readiness and analyze the factors for creating conditions for broadband business entrepreneurship in order to create new generation of value-added chains and achieving lasting success for the Bulgarian society.

The aim of the authors' own research was to identify the technological readiness and analyze the factors for creating conditions for broadband business entrepreneurship in order to create new generation of valueadded chains and achieving lasting success for the Bulgarian society. The focus is to analyze the impact of digital entrepreneurship in small, medium-sized and large enterprises conducting business activity in Bulgarian enterprises. A questionnaire was used to collect data from a sample of 176 SMEs in Plovdiv area which were selected through stratified random sampling method.

The results of the study show that the technological readiness for building effective value chains in Bulgaria is at a relatively high level. It is necessary to build an adequate digital infrastructure, improve the legal framework, invest in human resources training, increase the innovation activity of enterprises.

Keywords: broadband business entrepreneurship, complex reengineering, digitalisation, industry 4.0 .

JEL: D80, L26, 032

\section{Introduction}

growing number of reports and Astudies recognize the key role that digital technologies can play in improving the business landscape across the world. It

\footnotetext{
1 This paper is funded from the National Science Program "Healthy foods for a strong bioeconomy and quality of life" of the Ministry of Education and Science, approved by decision of the Council of Ministers №577 / 17.08.2018, contract N 68 / NSP under work package 4.2 "Regional Ecosystems for Bio-Economy"

Professor., Dr. Sc (Econ) at Department of Industrial Business and Management, University of Food Technologies - Plovdiv, Bulgaria ** Associate Prof., PhD at Department of Industrial Business and Management, University of Food Technologies- Plovdiv, Bulgaria
} 


\section{Articles}

provides an opportunity for both developed and less developed countries to achieve sustainable growth and to create decent jobs and thereby to contribute to the achievement of the sustainable development goals. Broadband entrepreneurship can strongly contribute to reducing poverty and creating prosperity and livelihoods. Furthermore, digital entrepreneurs can reap the benefits of the global market. Young people can develop their capacity to build start-ups and innovative community initiatives by using digital technologies as a support. Digitalization can also create opportunities in sectors such as cultural and creative industries which employ proportionately greater numbers of young people and women.

Digital hubs and scalable digital services and products are emerging in developing countries. In addition to creating growth and jobs they serve as a way to address local problems using digital means. Broadband entrepreneurship is driven by so called „frugal innovation", meaning design of products and services that are affordable and durable, without having a focus on sophistication.

Nevertheless, analyses show that businesses - and SMEs in particular - often struggle with digital developments. There are barriers to cross-border trade, regulatory and administrative burdens, insufficient access to finance and digital skills in the workforce. Removing intermediaries, matching employers with their future employees, providing online education, adapting the educational material, giving people their first physical address and their first bank account are just a few of the areas that digital entrepreneurs have to address. In order to build innovation ecosystems, a number of measures are necessary.

Developing and applying the theory of complex reengineering (CR) Hadzhiev notices the emergence of a new technology related to the philosophy, goals and concepts of CR - broadband entrepreneurship (Hadzhiev, 2013). In the researcher's opinion, this technology predetermines the new nature of business management effort and becomes a useful tool for each of the CR concepts, especially the concept of developing and implementing business and/or corporate business models. As known, the concept of developing and implementing business and/or enterprise business models is based on the three-tier model (Diagnostic Model, Change Orientation Model, and Strategic Change Model).

\section{Literature review}

Broadband entrepreneurship is presented as an integrated entrepreneurship that can be applied in any field (competition, value innovation, divergence, convergence). It builds on classical entrepreneurship, drawing on the theory of prudent process management and CR theory. It is connected with rethinking, redesigning and perfecting complex business engineering. As Hadzhiev stated in the publication of Broadband Entrepreneurship "... there is a question of complex engineering of the main desires, processes, needs, information, products and services in a given sector, providing benefits for business, nature and society". Technology is a particular type of management effort that continually extends every sector, every kind of entrepreneurship by discovering and acquiring knowledge, provoking new behavior through the prism of natural laws and natural processes, human psyche and artificial intelligence (Ganchev\&Popov, 2011). Knowledge about broadband entrepreneurship is becoming an independent high-weight variable for the gaming business area. According to Hadzhiev, reengineering tools in the gaming business field for enterprise expansion are as follow: 


\section{Articles}

developing and implementing algorithms for synergy and achieve synergistic effects of different levels: global, international, national, industrial, sector, inter-sector, corporate, intercompany ;

$>$ developing and implementation of algorithms for reengineering the economic and the corporate culture;

$>$ developing and implementation of algorithms for instant orders and for immediate conclusion of transactions;

developing algorithms for innovation and innovation management at different levels: global, international, national, industrial, sectoral, cross-sectoral, business, intercompany;

$>$ development and implementation of algorithms for broadband shopping in the sector providing merger of wholesale and retail;

development and implementation of algorithms for the design of artificial intelligence useful for automation and robotic proceedings and businesses in sectoral and cross-sectoral processes (robots with no artificial intelligence are a pile of iron);

develpoment of algorithms for the implementation of both classical reengineering methods, systems, technologies and standards, as well as the systems SIX-SIGMA, CROSS SELING 1R, MANAGEMENT 3.0 (looks at management and marketing as an upgrade to the industrial era 1.0, that of the Information Age 2.0 based on values as a driver of modern development), AGILE (a series of methodologies in conducting modern dynamic processes), SKREEM (quick process framework for changes), KANBAN (processes for gradual improvements), TEAL (a method of attracting money and neglecting material assets as something shameful), RADICAL MANAGEMENT (the starting point is an organizational culture
Exploring the Technological Readiness of Bulgarian

Entrepreneurs to Create New Generation of Value-Added Chains

based on the friendly communication between management and employees and the understanding that the starting point for the business is the customer and all involved in the business process), TQM, GS1 and etc;

establish and implement algorithms by copying natural processes for solving specific technology and business problems;

establishment and implementation of algorithms for protection of the environment; development and implementation of algorithms to reduce food dependency and the growing desire for comfort.

Broadband entrepreneurship can also be seen as multilingual entrepreneurship when entrepreneurial activity is differentiated into different lanes/areas. Broadband is believed to increase the revenue potential for entrepreneurs, as well as reduce the costs of obtaining external resources. As potential entrepreneurial earnings increases, entrepreneurship becomes more attractive. The level of entrepreneurship should therefore rise. Three main reasons for increased potential earnings are presented below:

Broadband and Market Access: the increased diffusion of broadband and internet usage will enable entrepreneurs to "efficiently expose their companies, market and sell their products and services to a wider audience than they would have been able to afford to reach using the traditional methods" (Lawrence, 2011). For example, broadband enables activities such as e-commerce, through which retailers can reach customers in a much wider geographic area than through physical stores (Atasoy, 2011). The market potential therefore increases significantly for entrepreneurs with access to broadband. Numerous studies have verified the impact of market potential on entrepreneurship. Berry and Reiss claimed that thresholds exist to the regional population 


\section{Articles}

size for which firms establish themselves as going concerns. Also, they argued for a positive relationship between population size and firm entry rate. Sato et al. Verified the prevalence of this relationship as they found that an increase in population density by $10 \%$ raises the number of individuals intending to become entrepreneurs by approximately $1 \%$.

Broadband and Transaction Costs: increased internet usage allows for the establishment of an "effective inter-business collaboration" (Hsieh \& Lin, 1998 ). As small firms often suffer from limitations in various types of resources, broadband can reduce the transaction costs involved in obtaining these resources externally. According to Williamson (Williamson, 1991), transaction costs stem from asset specificity, information asymmetry, and opportunism. Based on this widely accepted theory, other scholars have argued that the increased prevalence of broadband and internet could reduce these factors, hence lower the transaction costs. Afuah (Afuah, 2015) argued that asset specificity, defined as the "degree to which an asset can be redeployed to alternate uses and by alternate users without sacrifice of productive value" is affected in three ways by increased internet usage. First, internet could facilitate low-cost information exchange about the asset and its value to other potential owners. Second, it reduces the site-specificity of assets as firms can exchange large quantities of information without actual physical interactions, reducing the dependency of geographic proximity to counterparts. Third, internet reduces the specificity of some information technology related assets by replacing them with its more standardized technology. Increased broadband and internet access also reduces information asymmetries (Wallace, 2004) by facilitating access to market prices through, for example, search engines and price-comparison websites. Costs of monitoring and enforcement can also be reduced, as information on and reputation of the potential counterpart becomes more accessible. In line with the theories of Coase (Coase, 1937), these developments should lower the optimal size of a firm. As transactions can be more efficiently handled through market exchange, the incentive for firms to internalize transactions diminishes (Londev, 2017). Lower transaction costs could thus indirectly increase the market potential for entrepreneurs, as potential customers become more inclined to purchase goods and services externally, as well as directly lower the costs for entrepreneurs to obtain resources externally.

\section{Broadband and Entrepreneurial} Opportunities: the potential earnings as an entrepreneur could also be positively impacted by new opportunities that arise due to widespread broadband access. Baumol expressed a view of entrepreneurship as individuals responding to opportunities for new products that arise due to technological progress (Baumol, 1986) . Eckhardt and Shane viewed changes in supply and demand as one way to categorize how these opportunities occur (Eckhardt \&Shane, 2003). On the supply side, Schumpeter identified five sources of opportunities including changes in the ways of organizing, new products or services, and new production processes. Exogenous shifts in demand factors such as perception and taste could similarly act as sources of opportunities. Afuah exemplifies this with internet replacing proprietary communication networks such as Electronic Data Interchange (EDI), in which only network members could exchange information. For example, if a supplier wanted to cooperate and communicate with a new retailer, the supplier had to invest in new EDI equipment in order to access the network specific to the retailer. With the introduction of internet, the supplier could use the same equipment for all relationships. Scholars have further argued that incumbent corporations and organizations 


\section{Articles}

might not automatically respond to these opportunities, for example due to uncertainties about the value of new knowledge, information asymmetries and discrepancies between the new idea and core competencies. This would consequently leave room for entrepreneurial exploits. In accordance with Carree et al. who claimed that "technological change may be the most significant determinant of expanded entrepreneurial opportunities in the late twentieth and early twenty-first century", our belief is that increased diffusion of broadband will allow for new entrepreneurial opportunities to arise (Carree at al, 2010). These could either be supply-oriented, for example through new ways of using the internet for organizational purposes, or demand -oriented, as consumers demand more IT-solutions.

Increased broadband penetration can also be expected to facilitate the discovery of new opportunities. Heger et al. argued that broadband access reduces proximity not only to customers, but also to "knowledge incubators", such as universities, other institutions, and, in particular, local business communities. According to Harhoff, these networks facilitate entrepreneurial activities through "knowledge spillovers", especially in technology-intensive industries. This line of reasoning is supported by scholars such as Christensen and Peterson, who argued that encounters between an individual and his network are important sources of new ideas.

To clarify the impact of broadband penetration on entrepreneurial risks, we will discuss how broadband affects new firm survival:

A. Impact on Entrepreneurial Risks: Based on the many empirical studies conducted in this field (Wallace 2004, and Berry, 2007), two variables, market positioning and financing, are believed to be of particular importance. As entry into an industry often entails investments, entrepreneurs are likely to lack the capital for these relative to larger
Exploring the Technological Readiness of Bulgarian

Entrepreneurs to Create New Generation of Value-Added Chains

firms. As support for this hypothesis. White found that small businesses are more present in industries with low capital to labor ratios. As entrepreneurs therefore tend to be more dependent on financing, this factor might pose as significant obstacle for survival. Bates found that American males who became self -employed between 1976 and 1982 and received above -average rates of financing were less likely to exit than their counterparts. Similar results have been found by Taylor. As internet have made business activities more digitalized and less capital intensive (Porter, 2001; Parker, 2004), the need for financing investments has reduced and the risk of entrepreneurship has consequently decreased. Furthermore, scholars have argued that firms having a dynamic or diversified product range as a result of, for example, re-positioning in the event of market changes that creates new niches, increases the chance of entrepreneurial survival. Brüderl et al. found supporting results showing that survival rates were higher for firms with national rather than local market coverage. As broadband increases "firms' ability to move more quickly from idea to product" as well as to reach a wider market, entrepreneurial survival rates should increase.

Given that broadband has a positive impact on new firm survival rates, the risk associated with entrepreneurial activities is expected to have decreased, making entrepreneurship a more attractive alternative relative employment.

\section{B. Impact on Expected Employment} Earnings and Risks - There have historically been doubts as to whether information and communications technologies (ICT) impact productivity. Scholars have discussed the "productivity paradox", classically described by Robert Solow as, "You can see the computer age everywhere but in the productivity statistics" (Solow, 1987, p. 36). 


\section{Articles}

In recent years, increasing evidence have been found on the positive effects of ICT on productivity (Bosworth and Triplett, 2003; Carare et al., 2009; Ganchev, 2017).

One could therefore expect some of the increased productivity to be captured by higher wages, increasing expected employment earnings. Scholars such as Gillet et al. (2006) and Kolko (2010) have tried to prove this hypothesis empirically but found no significant evidence of it to be true. According to Kolko (2010), this could be due to flexible labor markets in the sense that immigration of workers keeps wages from rising. Broadband could also be argued to impact some determinants of employment risk, for example by substituting some labor functions and by increasing labor market efficiencies through increased use of e -recruiting. However, due to the lack of research in this field, it becomes difficult to assess the net impact. Despite the results from prior studies, one might suspect that increased broadband penetration increases the risk-weighted wages as a consequence of productivity increases. In particular, the argument by Kolko is not fully convincing in a cross-country setting where labor migration between countries is more restricted.

\section{Potential Lagged Effect of Broadband} -One might suspect there to be a timelagbefore a given increase in the number of broadband subscriptions is reflected in higher levels of entrepreneurship. It could be argued that individuals must pass through a process of "organizational emergence", which consists of activities such as preparing a plan or buying or renting facilities, before they start their business. Few prior empirical studies on the economic effects of broadband have however used lagged variables for other reasons than to correct for reverse causality. Kolko (2012) investigated the possibility of an impact from broadband expansion 1992-1999 on employment growth 1999-2006 and found no significant results, concluding that there are no long lags in the relationship. Czernich et al. also use time-lags of their independent variable, but conclude that most of the effect of broadband on economic growth occurs contemporaneously.

D. Value chains - Two core elements are embedded in definition of a value chain: chain and value. The chain component of value chain refers to a supply chain-the processes and actors that take a product from its conception to its end use and disposal (this chain can also be seen as the life cycle of the product). For a single food or commodity product, for example, a supply chain comprises the processes and actors that take a food from its production on the farm-including the inputs into that production-to the consumer and to its disposal as waste. The supply chain incorporates each of the transformations required to turn it into the final product. "Value" refers to the value added to the product by activities at each step in the chain (for example, rice sells for EuroX at the farmgate, but cleaning it makes it worth Euro $X+3$ ), as well as the value created by the product and activities and then captured by each of the actors involved (for example, EuroX for the farmer and EuroX +3 for the retailer). The "added" part means the difference between the total revenue created by the product and the costs of the materials, labor, and other inputs used to produce it, which can then be captured by the actors along the chain. "Upgrading" refers to the various ways that actors can capture more value by changing their products, processes, and functions.

As can be concluded from the discussion above, increased broadband penetration is believed to be reflected in significantly higher entrepreneurial earnings, as well as lower entrepreneurial risks. While broadband could also potentially raise the risk-weighted employment earnings through increases in 


\section{Articles}

productivity, these increases are expected to be significantly lower. Although the magnitudes of our arguments have not been quantified, this is to be expected given the many more channels through which broadband penetration increases the utility of entrepreneurship. Thus, our hypothesis is that increased broadband penetration has a significant and positive impact on the technical readiness for creating effective value-added chains. This would make entrepreneurship a more attractive alternative for many individuals, and should therefore result in a higher number of new business registrations.

Based on the above understandings, we set out to identify them the main factors for creating the conditions for implementation of the tools of broadband entrepreneurship, to analyze these factors in order to draw attention to the technological readiness and opportunities for achieving lasting success for the Bulgarian society.

\section{Research methodology}

The aim of the authors' own research was to identify the technological readiness and analyze the factors for creating conditions for broadband business entrepreneurship in order to create new generation of value-added chains and achieving lasting success for the Bulgarian society. The focus is to analyze the impact of digital entrepreneurship in small, medium-sized and large enterprises conducting business activity in Bulgarian enterprises. The survey used purposive sampling. It was conducted in XI and XII of 2017 on a group of 176 enterprises classified, according to the size of employment, as small, medium-sized and large enterprises. Stratified sampling was used to select the enterprises from the food industry, the financial sector, retail, tourism, heavy and light industry. In this case we sent an e-mail to the membership of Bulgarian Chamber of Commerce and Confederation of the Employers and Industrialists in Bulgaria -
Exploring the Technological Readiness of Bulgarian

Entrepreneurs to Create New Generation of Value-Added Chains

CEIBG invited them to participate in the survey. A stratified random sample was a useful blend of randomization and categorization, which enabled both a quantitative and qualitative process of study to be undertaken. A survey questionnaire was addressed both to production companies and services companies. The size of the research sample certainly allows the authors to draw initial conclusions and identify regularities that can be verified during the proper studies. Factor analysis was used in this study to measure the validity of the instrument. The questionnaire was designed on a ten point Scale which ranged from 1 to 10 point, where 1 means very low evaluation, and 10 - very high evaluation. The results presented below are only a fragment of the empirical studies conducted.

\section{Analysis and results}

The dominating group among the enterprises surveyed comprised small companies employing from 10 to 49 people, which accounted for $74 \%$ of all the companies surveyed (fig.1).The second dominating group comprised medium-sized enterprises employing from 50 to 249 people, which accounted for $17 \%$ of all the enterprises surveyed, whereas $9 \%$ of those surveyed were large enterprises, employing over 250 people. The largest group of enterprises, representing $68.5 \%$, has operated on the market for over 10 years; $21.4 \%$ of enterprises declared functioning on the market for 5 to 10 years, whereas the remaining companies have conducted their business activity for a year to 5 years. The enterprises surveyed did not include companies entering the market, i.e. those functioning for a period shorter than1 year. Among the enterprises surveyed, almost 63\% declared good current financial condition, and over $26.3 \%$ assessed their financial condition as very good. Only $1 \%$ of all the respondents assessed their current financial situation as very poor or poor. 


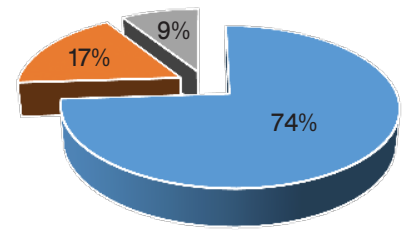

- Small - Medium-Sized - Lardge

Fig. 1. Distribution the respondents by size of the companies

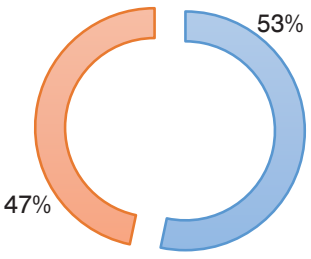

$\square$ Male $\square$ Female

Fig. 2. Distribution the respondents by sex

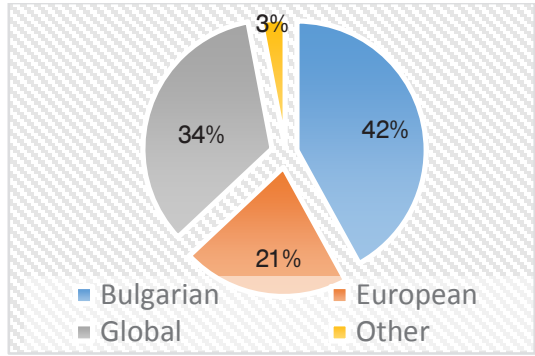

Fig. 3. Market orientation
$53 \%$ of men and $47 \%$ of women participated in the study (fig.2). The presented companies have different market orientation (fig.3) $42 \%$ work on the Bulgarian market, $34 \%$ on the Global market and $21 \%$ on the European market.

Factor analysis was used in this study to measure the validity of the instrument. The questionnaire was designed on a ten point Scale which ranged from 1 to 10 point, where 1 means very low evaluation, and 10 - very high evaluation. The factors that have been investigated are grouped into separate groups as follows: Group ${ }_{g} \mathrm{~A}^{\text {(6 }}$ - the availability of appropriate infrastructure for active and passive entrepreneurial subjects respectively; Group „,B“ - knowledge of the relevant market players; Group "C. business requirements in the relevant market area; Group , ,D“ - potential for marketing and financial evaluation of the respective business activity; Group ,E“ - opportunities to rethink the business. Each group includes specific factors that are rated by the respondents on a scale of 1 to 10 (see Table 1):

Table 1. Systematization of the surveyed factors by specific groups

\begin{tabular}{|c|c|}
\hline Group & Composite factors \\
\hline „A“ & $\begin{array}{l}\text { - a1 - availability of appropriate digital infrastructure; } \\
\text { - a2 - assessment of the development of the productive forces at the destination of the the subject and the } \\
\text { concentration of production (coefficient of localization); } \\
\text { - a3 - concentration of consumption at the destination of the subject; } \\
\text { - a4 - stage of development of scientific and technical progress and innovation activity; }\end{array}$ \\
\hline „B“ & $\begin{array}{l}\text { - } \text { b1 - an assessment of the market's need for the relevant business activity of the subject; } \\
\text { - } \text { b2 - assessment of knowledge about the specific features of the market and marketing; } \\
\text { - } \text { b3 - structure of the market share of competitors in the sector; } \\
\text { - } \quad \text { b4 - knowledge's degree of the legal and political factors affecting the market. }\end{array}$ \\
\hline „C“ & $\begin{array}{l}\text { - } \mathbf{c 1} \text { - the potential of the subject to meet the political and legal requirements for the business concerned; } \\
\text { - } \mathbf{c 2} \text { - fulfillment of economic requirements related to the business concerned; } \\
\text { - } \mathbf{c 3} \text { - fulfillment of currency-financial requirements; } \\
\text { - } \mathbf{c 4} \text { - fulfillment of social requirements; } \\
\text { - } \mathbf{c 5} \text { - human resources organization; } \\
\text { - } \mathbf{c 6} \text { - preparation and implementation of innovative, manufacturing, transport, insurance, forwarding and others } \\
\text { activities. }\end{array}$ \\
\hline
\end{tabular}




\begin{tabular}{|c|c|}
\hline Group & Composite factors \\
\hline „D“ & $\begin{array}{l}\text { - } \mathbf{d 1} \text { - marketing knowledge is recommended for the "Logistic model Service Quality " } \\
\text { - } \mathbf{d 2} \text { - for the financial evaluation of the respective business activity is recommended evaluation of structure, } \\
\text { accessibility, volume and speed use of capital for the relevant business activity; }\end{array}$ \\
\hline „E“ & $\begin{array}{l}\text { - } \mathbf{e} 1 \text { - the nature and type of business processes; } \\
\text { - } \mathbf{e} 2 \text { - the nature and type of business communications; } \\
\text { - } \mathbf{e} 3 \text { - the nature and type of business negotiations; } \\
\text { - } \mathbf{e} 4 \text { - investment interventions (for SMEs surveyed, low-performance indicators are for circular economy, GS1, } \\
\text { artificial intelligence, information networks and applications, robotics, industry 4.0, intelligent technologies, synergy); } \\
\text { - } \mathbf{e 5 ~ - ~ i n t e r v e n t i o n s ~ t o ~ r e c o n s i d e r ~ a p p r o a c h e s ~ a n d ~ e x i t ~ s y s t e m s ~ m a r k e t s ~ ( f o r ~ S M E s ~ s u r v e y e d ~ l o w - p e r f o r m a n c e ~} \\
\text { indicators are for mergers and acquisitions, sales channels, transnationalization, public-private partnerships, cutting } \\
\text { edge technologies and innovation / technological, product, financial/). }\end{array}$ \\
\hline
\end{tabular}

The scale for measuring and evaluating the indicators on the above mentioned factors is multidimensional with an ordered structure. The possible average value of the indicators is
50. The averaged assessment of the indicators for the surveyed SMEs is 23 and for the large companies surveyed is 38 .

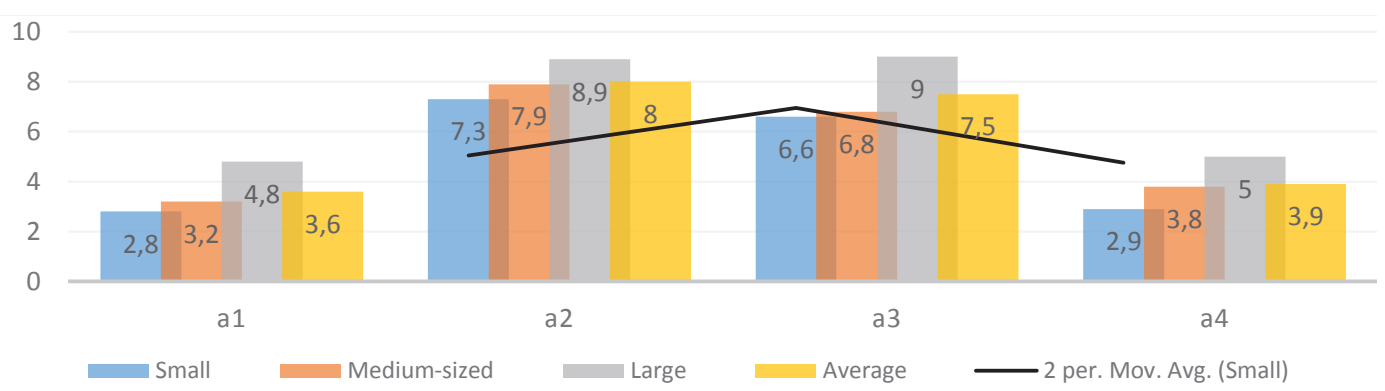

Fig. 4. Assessment of Group "A" Factors; Source: Own Field Survey, 2017

The results of the Group "A“ Factors rating are shown in Fig. 4. It is noted that the factors a1 and a4 are the least appreciated from the three types of enterprises. The highest average score is given on factor a2 (8), large companies give the highest scores averaged estimates of factors a2 $(8,9)$ and a3 $(7,3)$. Respondents ranked the lowest with the availability of appropriate digital infrastructure, as well as the low level of research and the need to increase innovation activity. This leads to the conclusion that companies have a high awareness of the need to create infrastructure and increase innovation activity in order to increase their competitiveness through their participation in value chains.

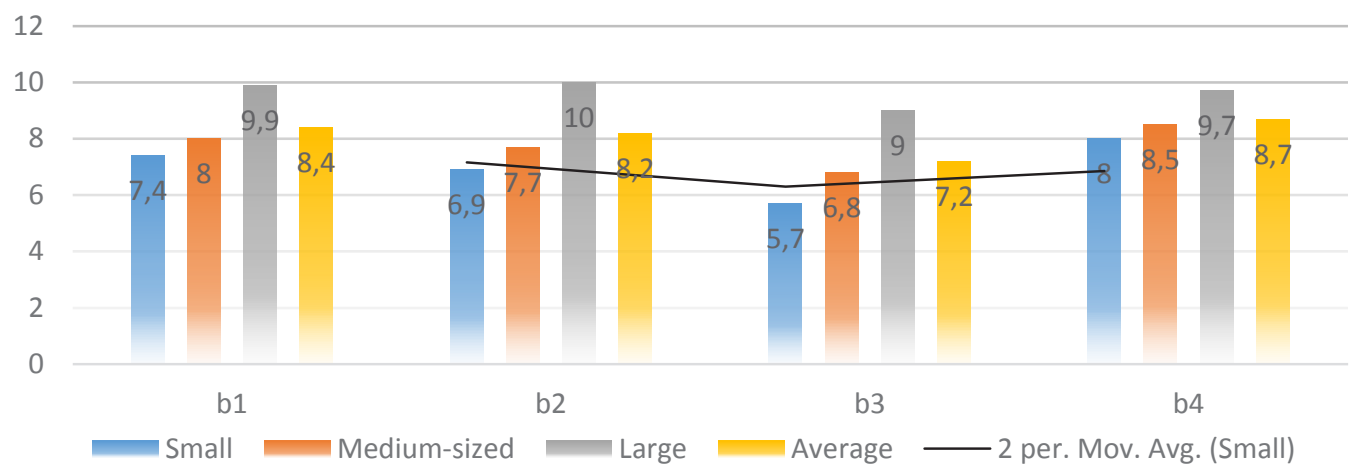

Fig. 5. Assessment of Group "B" Factors; Source: Own Field Survey, 2017 


\section{Articles}

The results of the Group „B“ Factors rating are shown in Fig. 5 . It is noted that the factor b3 is the least appreciated from the three types of enterprises. The highest average score is given on factor b4 $(8,7)$, large companies give the highest scores averaged estimates of factors b2 $(10)$ and $\mathbf{b} 1(9,9)$. This leads to the conclusion that large companies are more in tune with market needs and regularly rethink the specifics of individual market segments. While small and medium-sized enterprises are more aware of the legal and political factors that could affect the market. All three types of enterprise are very poorly monitoring and complying with the strategies of competitors in the industry.

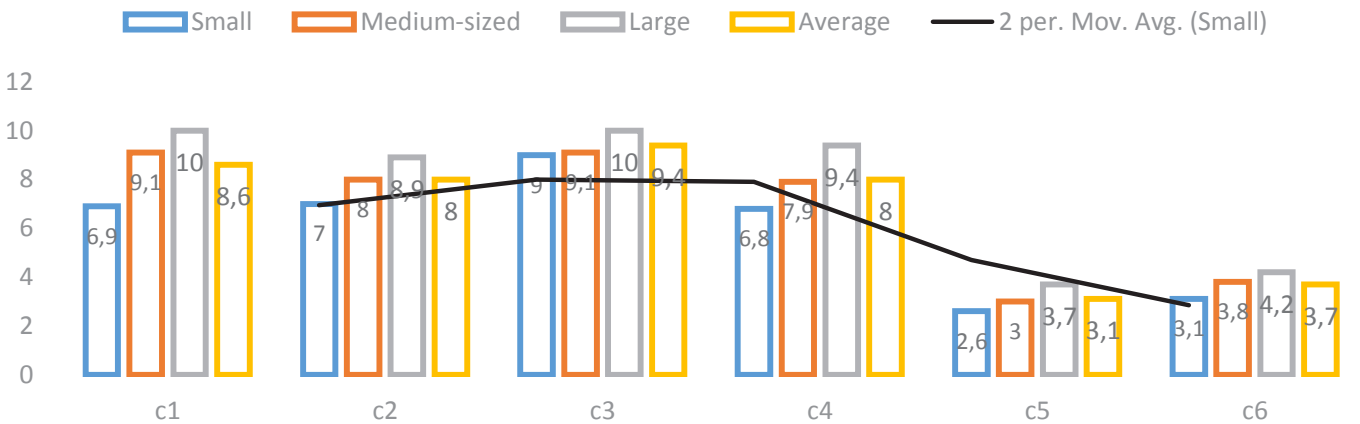

Fig. 6. Assessment of Group "C" Factors; Source: Own Field Survey, 2017

In the assessment of the Group "C" Factors (see Fig.6), it is noted that the factors with the lowest average aggregate rating are $c 5(3,1)$ and $c 6(3,7)$. The highest average score is given on factor c3 $(9,4)$, large companies give the highest scores averaged estimates of factors c1 (10), c3 (10) and $c 4(9,4)$. From this, it can be concluded that the respondents, regardless of their size, are aware of the lack of qualified human resources and the willingness to innovate. All respondents consider that they meet the legal and financial requirements, as well as the requirements of the society.

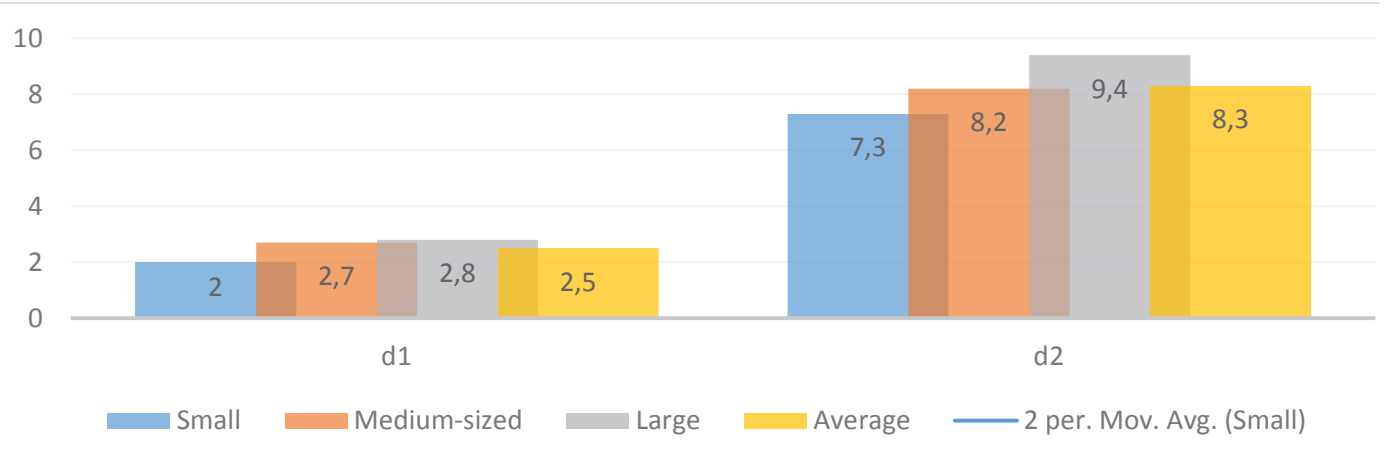

Fig. 7. Assessment of Group "D" Factors; Source: Own Field Survey, 2017

The results of the Group „D“Factors rating are shown in Fig. 7. It is noted that the factor d1 is the least appreciated from the three types of enterprises. The highest average score is given on factor d2 $(8,3)$, large companies give the highest scores averaged estimates of factor $\mathbf{d} \mathbf{2}(9,4)$, compared to the other representatives of small and mediumsized enterprises - respectively $(7,3)$ and $(8,2)$. All respondents believe that the modern 


\section{Articles}

Logistics models for quality service are not yet sufficiently implemented. On the other hand, the financial evaluation includes an assessment of the structure, accessibility, volume and speed of the use of capital for the respective business activity. This leads
Exploring the Technological Readiness of Bulgarian

Entrepreneurs to Create New Generation of Value-Added Chains

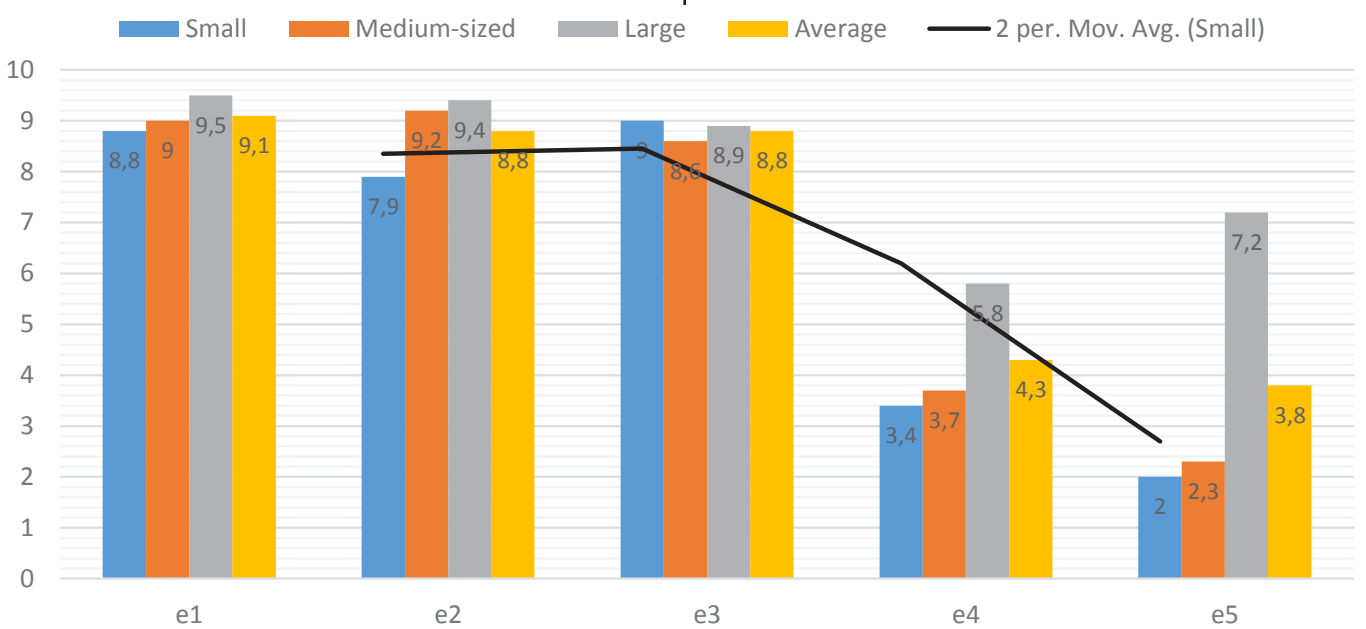

Fig. 8. Assessment of Group "E" Factors; Source: Own Field Survey, 2017

In the assessment of the Group „E $\mathbf{E}^{\text {“" Factors }}$ (see Fig.8), it is noted that the factors with the lowest average aggregate rating are e5 $(3,8)$ and e4 $(4,3)$. The highest average score is given on factor e1 $(9,1)$, followed by e2 and e3, which receive the same score $-8,8$. It is noted that large enterprises give a relatively high individual estimate of factor e5 (7.2), as opposed to low individual ratings of SME representatives respectively (2) and $(2,3)$. The conclusion can be drawn that the Bulgarian enterprises still to the conclusion that Bulgarian enterprises have the potential to integrate into effective value chains, as they have the necessary financial knowledge, but there are still no good business models for logistics and building effective logistics systems.

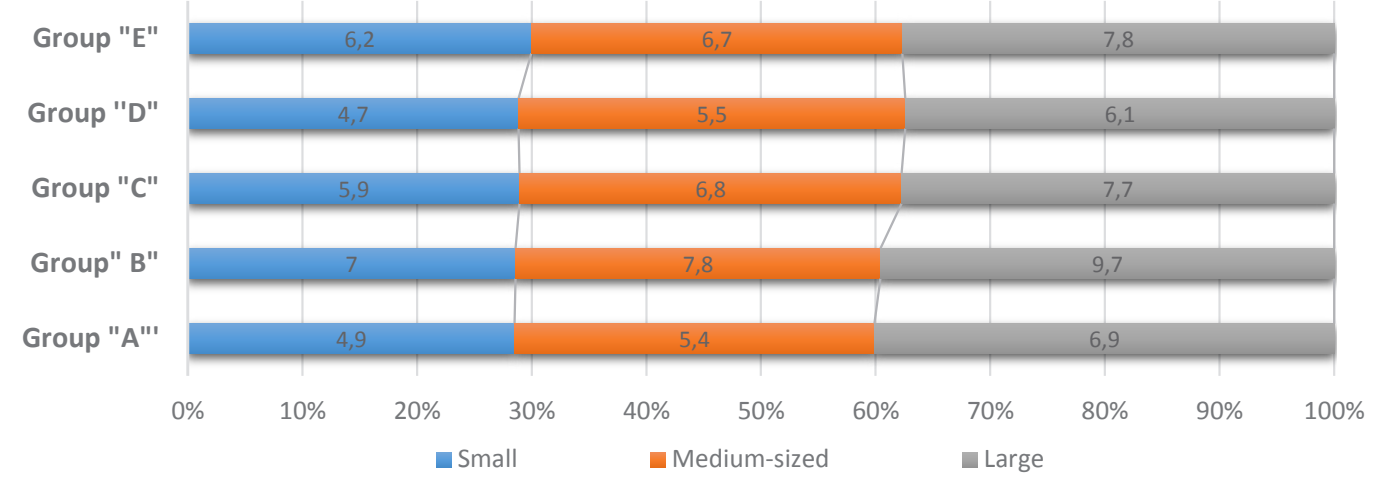

Fig. 9. Average rating by group of factors; Source: Own Field Survey, 2017 


\section{Articles}

The average individual ratings of the different types of enterprises (small, medium and large) by the different groups of factors show that relatively the highest estimates are given by large enterprises, followed by mediumsized enterprises ( see Fig.9). An important conclusion can be drawn here, namely that a better technological, resources and policylegal environment needs to be created to stimulate broadband entrepreneurship among SMEs. A comparative analysis of the factors shows that large enterprises are more technologically ready to build value chains, although small and medium-sized enterprises are more flexible to change and show greater maturity in their business processes, as well as ensuring better conditions for developing broadband entrepreneurship.

In particular, management efforts should be directed to improving the lowestperforming indicators. This will allow to create better conditions for the implementation of broadband entrepreneurship tools, and hence to create sustainable success for the Bulgarian business, by enhancing their technological readiness to build effective value chains. It could be started by building digital infrastructures to unite the efforts of Bulgarian companies at the sectoral and intersectoral level and thus to achieve a synergic and multiplier effect.

Similarly, setting up entrepreneurial centers and clubs and encouraging the entrepreneurial efforts of passive entrepreneurs by finalizing their efforts to obtain a final product or service will help create and operate a Bulgarian market for innovation and smart products.

\section{Conclusion}

The purpose of this study was to explore the effect of entrepreneurial mindset on the technological readiness for creating value-added chains and remain competitive. Entrepreneurs with an entrepreneurial mindset see needs, problems and challenges as opportunities and develop innovative ways to deal with the challenges, and exploit and merge opportunities. Acquiring an entrepreneurial mindset requires re-learning how to motivate themselves, identify business opportunities, take risk, and become creative and innovative.

The results of the study show that the technological readiness for building effective value chains in Bulgaria is at a relatively high level. It is necessary to build an adequate digital infrastructure, improve the legal framework, invest in human resources training, increase the innovation activity of enterprises. Respondents ranked the lowest with the availability of appropriate digital infrastructure, as well as the low level of research and the need to increase innovation activity. This leads to the conclusion that companies have a high awareness of the need to create infrastructure and increase innovation activity in order to increase their competitiveness through their participation in value chains. The large companies are more in tune with market needs and regularly rethink the specifics of individual market segments. While small and medium-sized enterprises are more aware of the legal and political factors that could affect the market. All three types of enterprise are very poorly monitoring and complying with the strategies of competitors in the industry. The Bulgarian enterprises still have poorly implemented interventions on the implementation of GS1, artificial intelligence, information networks and applications, robotics and other industry 4.0 tools, intelligent technologies, synergies, mergers and acquisitions, sales channels, transnationalization and and others. On the other hand, Bulgarian companies show a high degree of technological readiness to build value chains, as they are well aware of 


\section{Articles}

their business processes and can adequately manage them.

The study concludes that in order to find a means to increase the entrepreneurial mindset of entrepreneurs, it is necessary to understand factors that link directly with entrepreneurial mindset such as; continuous education, growth mindset, creativity, motivation and risk taking propensity.The entrepreneur must be able to always scan the environment and seek new business opportunities to stay ahead of competitors, he or she must also become very innovative to improve on processes, products value chains, to remain attractive and create customer loyalty, the entrepreneur must bring new processes and products into the market and SMEs must take modest levels of risk in order to succeed.

This also proves the formulated hypothesis, namely that the promotion of broadband entrepreneurship will significantly affect the technological readiness to create effective value chains. This would make entrepreneurship a more attractive alternative for many individuals, and should therefore result in a higher number of new business registrations and increased innovative activity.

\section{References}

Hadzhiev, B. (2012), Complex reengineering of business organizations in the conditions of global economy (by the example of food industrial organizations), ISBN: 978-954-240215-2, UFT, P.,;

Hadzhiev, B. (2013), Development of the Bulgarian Economy through Complex Reengineering (CoR), „Prerequisites and

Opportunities for Industrial Growth in Bulgaria" ISBN 978-954-644-494-3. UNWE, Hadzhiev, B., (2017); Broadband entrepreneurship.;

Hadzhiev, B. et al., (2016), Challenges to Contemporary Entrepreneurship / Studies / ISBN 0013-2992, C.,;
Exploring the Technological Readiness of Bulgarian

Entrepreneurs to Create New Generation of Value-Added Chains

Solins, B. (2015). The new business model. Success in the consumer revolution requires change;

Afuah, A. (2015), Redefining firm boundaries in the face of the Internet: are firms really shrinking? Academy of Management Review, pp. 34-53

Ganchev D., Popov G.,Inovatsionnata aktivnost na predpriemachite ,Konferentsiya na Asotsiatsiyata na prepodavatelite po ikonomika I upravlenie na industriyata, Sbornik dokladi, str. 175-178, Tryavna,2011, ISSN1314345.

Atasoy, H., (2011), The Effects of Broadband Internet Expansion on Labor Market Outcomes. Job Market Paper Department of Economics, University of Illinois, p.234

Bosworth, B. P. \& Triplett, J. E. (2003). Productivity measurement issues in service industries:'Baumol's disease' has been cured. Federal Reserve Bank of New York Economic Policy Review, pp. 23-33

Bates, T.. Race, (1997), Self-Employment and Upward Mobility: An Illusive American Dream. Baltimore: Johns Hopkins University Press

Baumol, W. J. (1986), Entrepreneurship and the Long Run Productivity Record. NYU, Working Papers No. 86-04,

Berry, S. \& Reiss, P.( 2007), Empirical models of entry and market structure. In Armstrong, M., \& Porter, R. (eds.). Handbook of Industrial Organization, Volume 3, Chapter 29. Amsterdam: North-Holland

Carree, M., Thurik, R., van Stel, A., Wennekers, S. (2010). The relationship between entrepreneurship and economic development: is it U-shaped?Foundations and Trends in Entrepreneurship, pp.167-237

Coase, R. H. (1937), The Nature of the Firm. Economica, pp.386-406.

Christensen, P. S. \& Peterson, R. (1999), Opportunity Identification: Mapping the Sources of New Venture Ideas,10th annual 


\section{Articles}

Babson Entrepreneurship Research Conference. Aarhus: April 4-6

Czernich, N., Falck, O., Kretschmer, T., Woessmann, L. (2011), Broadband infrastructure and economic growth. The Economic Journal, pp.505-532

Evans and Siegfried, Evans, L. B. \& Siegfried, J. J. (1994), Empirical studies of entry and exit: A survey of the evidence.

Review of Industrial Organization, pp 121155

Eckhardt, J. T. \&Shane, S. A. (2003), Opportunities and Entrepreneurship. Journal of Management, pp. 333-349

Ganchev D. (2017), Foreign direct investments and regional economic performance in Bulgaria, Trakia journal of science, Fourth international scientific conference, "Business and Regional development', ISSN 1313-706, pp.216-222

Harhoff, D., Stahl, K., Woywodes, M. Legal form, growth and exit of West German firms empirical results for manufacturing, construction, trade and service industries. The Journal of Industrial Economics, 1998,pp. 453-488

Hsieh, C. \& Lin, B.( 1998) Internet commerce for small businesses. Industrial Management \&Data System, pp. 113-118

Heger, D., Rinawi, M., Velth, T. (2011), The Effect of Broadband Infrastructure on Entrepreneurial Activities: The Case of Germany. Mannheim: ZEW -Centre for European Economic Research, Discussion paper No11

Kolko, J. (2012), Does Broadband Boost Local Economic Development?. San Francisco, CA: Public Policy Institute of California, Broadband and local growth. Journal of Urban Economics, pp. 100-113
Londev A.,(2017), "Financial fraud and tax speculation, Politics and Security Journal, HSSE, Plovdiv, Vol.1, ISSN 2535-0358, pp. 131-137

Lawrence, J.E. \& Tar, U.A. (2011), The Potentials of ICT infrastructure in a developing economy: the case of small business in Kurdistan Region, Iraq. Information, Society and Justice, pp.101-119

Parker, S. C. (2004), The Economics of Self-Employment and Entrepreneurship. Cambridge: Cambridge University Press

Porter, M.. (1979), How Competitive Forces Shape Strategy. Harvard Business Review, pp: 137-146.;

Porter, M ., (2001), Strategy and the Internet. Harvard Business Review, pp 62-78

Solow R., (1987), We'd better watch out, The New York Times: Book Review. July 1219

Schumpeter, J. A. (1934), The Theory of Economic Development Cambridge, MA: Harvard University Press,

Sato, Y., Tabuchi, T., Yamamoto, K., (2012), Market Size and Entrepreneurship. Journal of Economic Geography, pp.234-257

Taylor, M. P. (1996), Earnings, independence or unemployment: why become selfemployed?, Oxford Bulletin of Economics and Statistics,. pp. 253

Williamson, O. E.,(1991) The Economic Institutions of Capitalism. New York Free Press,1991; Comparative economic organization: An analysis of discrete. Administrative Science Quarterly, pp.269-296 Wallace, P. (2004), The Internet in the Workplace: How New Technology Is Transforming Work. Cambridge: Cambridge University Press 